VERSITA

Course notes

DOI: 10.2478/rrlm-2013-0034

\title{
Tubular injury in multiple myeloma
}

\author{
Afectarea tubulară în mielomul multiplu
Cristian Balgradean ${ }^{1,3}$, Hortensia Ionita $^{2,3}$, Ioana Ionita ${ }^{2,3 *}$, Cristina Gluhovschi ${ }^{1,3}$, Florica Gadalean ${ }^{1,3}$, Ligia Petrica ${ }^{1,3}$ \\ 1. Dept. of Nephrology, County Clinical Emergency Hospital Timisoara; \\ 2. Dept. of Hematology, Clinical Hospital No.2 Timisoara; \\ 3. "Victor Babes" University of Medicine and Pharmacy, Timisoara, Romania
}

Received: $9^{\text {th }}$ January 2013; Accepted: $1^{\text {st }}$ September 2013; Published: $14^{\text {th }}$ September 2013.

\section{Multiple myeloma - clinical \& labora- tory features; diagnostic criteria}

\section{Epidemiology}

According to the literature, multiple myeloma (MM) may be attributed almost $1 \%$ of all cases with neoplasia and about $10 \%$ of hematologic malignancies in the USA $(1,2)$. The annual incidence rate in the USA is approximately 4-5 per 100.000 individuals. A similar incidence rate has been reported in the UK and in Europe (3-5).

The incidence is equal in all races and geographic locations, and varies by ethnicity; in African Americans and Blacks from Africa this is increased 2 to 3 fold as compared to that one in Caucasians $(6,7)$. By contrast, the incidence is lower in Asians from Japan and in Mexicans $(7,8)$. Moreover, multiple myeloma occurs more frequently in men than it does in women (approximately 1.4:1) (7).

The risk of developing $\mathrm{MM}$ is approximately 3.7-fold higher for persons with a first- de- gree relative suffering from the disease; also, it has been reported in identical twins, and in four members spanning three generations in one family (9).

\section{Clinical findings}

Upon diagnosis, the vast majority of patients with MM present with symptoms related to the infiltration of plasma cells into the bone or other organs, or to kidney injury resulting from excess light chains. In a retrospective study conducted on 1027 consecutive patients diagnosed with MM in a single hospital, the authors found the following symptoms on admission (6):

- Anemia of unexplained cause - 73\%;

- Bone pain - 58\%;

- Elevated serum creatinine - $48 \%$;

- Fatigue - 32\%;

- Hypercalcemia - 28\%;

- Weight loss - 24\%.

Anemia. Normocytic, normochromic anemia $(\mathrm{Hb} \leq 12 \mathrm{~g} / \mathrm{dL})$ is found in $73 \%$ of patients upon diagnosis, and in $97 \%$ of individuals at a certain point in the course of the disease (6).

${ }^{*}$ Corresponding author: Ioana Ionita, Clinical Hospital No.2 Timisoara - Department of Hematology, Timisoara, Str. Gh.Dima nr.5, Tel: +40-256432886, E-mail: mdioanaionita@yahoo.com 
This type of anemia can be caused by bone marrow replacement, kidney damage, and by dilution in the case of a large M-protein.

Bone pain. More frequently in the back or chest, and less often in the upper or lower extremities, bone pain is present at the time of diagnosis in $60 \%$ of patients (6). This type of pain is commonly induced by movement and does not occur during night, except with change of position.

Renal disease. Serum creatinine is increased in almost one-half of patients at the time of diagnosis (> $2 \mathrm{mg} / \mathrm{dL}$ in approximately $20 \%$ of cases); also, it should be underlined that renal function decline may be the initial manifestation of multiple myeloma $(6,10)$.

Radiculopathy, usually involving the thoracic or lumbosacral area, is the most common neurologic finding, subsequent to compression of the nerve by paravertebral plasmacytoma or occasionally by the collapsed bone.

Spinal cord compression from an extramedullary plasmacytoma and/or a bone fragment due to pathologic fractures of the vertebral body occurs in approximately $5 \%$ of patients.

Peripheral neuropathy is usually due to amyloidosis.

Central nervous system involvement. Intracranial plasmacytomas are rarely diagnosed and almost represent extensions of myelomatous lesions of the skull.

\section{Laboratory findings}

Monoclonal proteins. The presence of a monoclonal (M) protein in the serum or urine of patients is one of the major diagnostic criteria. It is known that $97 \%$ of patients with MM have an M-protein produced and secreted by the malignant plasma cells. This M-protein can be detected by serum protein electrophoresis (SPEP) and by urine protein electrophoresis (UPEP) performed from a 24-hour urine collection sample. Diagnosis accuracy is enhanced by immunofixation in the serum and urine (6).

The M-protein appears as a single narrow peak in the gamma, beta, or alpha- 2 region of the densitometer tracing, or as a dense, dis- crete band on the agarose gel. Serum immunofixation confirms the presence of the Mprotein and determines its type.

Typical monoclonal pattern. Kappa is the main light chain isotype found as compared with lambda, by a factor of 2:1. Data from the literature show that SPEP demonstrates a localized peak in $82 \%$ of patients with MM (6). Moreover, the use of serum protein immunofixation increases its sensitivity to $93 \%$.

Light chain myeloma. Almost $20 \%$ of patients with MM are only identified with light chains in the serum or urine, lacking expression of the immunoglobulin heavy chains. These ones are detected by UPEP and urine immunofixation. The incidence of renal failure is much higher in light-chain myeloma, case in which serum creatinine levels exceed $2 \mathrm{mg} / \mathrm{dL}$.

Furthermore, circulating monoclonal proteins may interfere with several lab tests performed on automated analyzers, either by precipitating during the analysis, or by specific binding capabilities. The most common artefacts are low levels for HDL-cholesterol, high levels for serum bilirubin, and altered measurement of inorganic phosphate. Although it is not considered a lab artefact, monoclonal serum proteins can increase the serum viscosity and ESR (this explains why in MM the ESR rate is greater than $20 \mathrm{~mm} / \mathrm{h}$, reaching values of $>100 \mathrm{~mm} / \mathrm{h}$ in one-third of patients).

Hypercalcemia. This laboratory finding occurs in $28 \%$ of patients with MM upon diagnosis. Calcium levels are above $11 \mathrm{mg} / \mathrm{dL}$ in almost $13 \%$ of cases and require treatment (6). The mechanism may be due to the binding of the monoclonal protein to calcium in the blood.

Urinalysis. In patients with MM the clinical findings consist of renal failure due to cast nephropathy. Alternatively, kidney disease associated with MM can be due to amyloidosis or light chain deposition disease. Urine dipstick can primarily detect albumin, not light chains, which can only be isolated from the 24-hour urine collection sample.

Peripheral smear. The common findings on peripheral smear are rouleaux forma- 
tion (over $50 \%$ of patients with MM), leukopenia (20\% of cases), and thrombocytopenia (5\% of patients) (6). The monoclonal plasma cells are rarely seen in the peripheral smear.

Bone marrow examination. The bone marrow sample contains $\geq 10 \%$ clonal plasma cells. Because of patchy bone marrow involvement, the bone marrow biopsy may show $<10 \%$ plasma cells in approximately $4 \%$ of patients. The diagnosis of MM is established, in case of patients with $<10 \%$ plasma cells, if other diagnostic criteria are present and/or after histopathologic confirmation.

\section{Diagnostic criteria}

The Mayo Clinic and International Myeloma Working Group criteria for the diagnosis of symptomatic MM focus on end-organ damage in making the diagnosis (11-14). The following criteria must be fulfilled in order to diagnose symptomatic cases of MM:

- Evidence of an M-protein in serum and/or urine; no specific level of M-protein is used as a cut-off value, mainly because approximately $40 \%$ of patients with symptomatic MM have an M-protein of $<3 \mathrm{~g} / \mathrm{dL}$;

- Presence of $10 \%$ or more clonal bone marrow plasma cells; also, it should be noted that $4 \%$ of patients may have less than $10 \%$ plasma cells, since marrow involvement may be focal. In these cases, diagnosis of MM can be made, by fulfilling other diagnostic criteria, and after histopathologic confirmation of a soft tissue or bone plasmacytoma;

- Evidence of related organ or tissue impairment which can include: hypercalcemia, renal failure, anemia, and lytic bone lesions detected by radiographic survey.

\section{Renal involvement in multiple myeloma}

Renal involvement is relatively common in patients suffering from MM. The occurrence of renal failure is heterogeneous and involves various mechanisms $(9,15,16)$. In two large-scale studies, $43 \%$ of 998 patients had serum creatinine levels > $1.5 \mathrm{mg} / \mathrm{dL} \quad(133$ $\mu \mathrm{mol} / \mathrm{L})(10)$ and $22 \%$ of 423 patients had serum creatinine levels $>2.0 \mathrm{mg} / \mathrm{dL}(177 \mu \mathrm{mol} / \mathrm{L})(16)$.

Several studies have underlined the correlation between severity of renal function impairment and patient survival rate. In the study conducted by Winearls, one-year patient survival was $80 \%$ in patients with serum creatinine levels below $1.5 \mathrm{mg} / \mathrm{dL}$ versus $50 \%$ in those with a serum creatinine above $2.3 \mathrm{mg} / \mathrm{dL}$ upon diagnosis (9). The response rate of renal failure to specific therapy seems to have prognostic value. In their study, Bladé et al showed that renal function recovery was reached in $26 \%$ of patients with renal failure at presentation. These patients had a survival rate of 28 months as compared to four months in those with irreversible renal failure (15).

The types of renal involvement in multiple myeloma can be summarized as follows (17): myeloma

Glomerular involvement in multiple

- Primary (AL or rarely AH) amyloidosis;

- Monoclonal immunoglobulin deposition (light chain deposition disease, heavy chain deposition disease, and light and heavy chain deposition disease);

- Collapsing FSGS due to drugs (e.g., Pamidronate);

- Miscellaneous (monoclonal cryoglobulinemia, proliferative glomerulonephritis due to monoclonal IgG deposition).

Tubular impairment in multiple myeloma

- Light chain cast nephropathy (myeloma kidney);

- Proximal tubule dysfunction (acquired Fanconi syndrome);

- Distal tubular dysfunction;

- Acute ischemic or toxic nephropathy.

Interstitial involvement in multiple myeloma

- Plasma cell infiltration;

- Tubulointerstitial nephropathy.

Other causes of renal involvement in multiple myeloma $(16,18)$ :

- Volume depletion (contributes to cast nephropathy, or acute tubular necrosis);

- Hypercalcemia, with or without nephrocalcinosis; 
- Hyperuricaemia;

- Tubulointerstitial nephritis (often drug-induced);

- Plasma cell infiltration of the kidneys;

- Hyperviscosity syndrome. (AKI) in multiple myeloma

Biomarkers of acute kidney injury

Although serum creatinine is the biomarker most frequently used in clinical practice for the diagnosis of acute renal failure, it was demonstrated that it is an insensitive and unreliable biomarker during acute changes in kidney function. Moreover, serum creatinine levels only increase when half of the kidney function is lost (19-22).

Urinary beta ${ }_{2}$-microglobulin represents a low-molecular weight protein filtered at the glomerular level and reabsorbed mainly in the proximal tubular cells. In clinical practice, this is used as an indicator of proximal tubule dysfunction (23).

Cystatin $C$ has an important role in the early detection of renal function alteration, even in mild renal function impairment, mainly because of its high sensitivity (24). This biomarker has a superior diagnostic value in the evaluation of AKI due to its short half-time (25).

Kidney injury molecule- 1 is increased in the urine of patients with tubulointerstitial lesions (25). Also, it represents a sensitive, non-invasive biomarker, utilized mainly in the early detection of AKI induced by ischemic mechanisms (26).

$\mathrm{N}$-acetyl-beta-D-glucosaminidase is produced by the proximal tubule cells and released in proximal tubule lesions. Increased levels are associated with tubulointerstitial nephropathies, AKI, and drug-induced nephrotoxicity $(24,26)$.

\section{Light chain cast nephropathy}

The most frequent tubulointerstitial lesion associated with MM is cast nephropathy. The characteristic findings are the presence of multiple acellular, homogeneous, and eosinophilic intraluminal proteinaceous casts. Also, the giant cell inflammatory lesions associated to these casts should be mentioned.

Several autopsy or biopsy studies underline myeloma cast nephropathy as the com- mon finding among patients with MM and clinically established renal involvement, accounting for almost 33-60\% of cases $(27,28)$.

Tubular atrophy and interstitial inflammation accompany the cast precipitation, some studies suggesting that the term of myeloma kidney is, therefore, more appropriate than cast nephropathy (18). Experimental data confirms that intraluminal cast formation is the main cause of AKI and most likely, the initiating step in the progressive deterioration in renal function.

Moreover, myeloma cast nephropathy (or myeloma kidney) refers to the onset of AKI or chronic kidney disease (CKD) determined by urinary monoclonal immunoglobulin light chains (Bence-Jones proteins) that precipitate in the urinary tubules (18). It is generally assumed that light chains have a molecular weight of $22.000 \mathrm{Da}$ and that they are freely filtered by the glomeruli and afterwards almost entirely reabsorbed by proximal tubular cells. The usual light chain excretion rate is $<30 \mathrm{mg} / 24 \mathrm{~h}$.

As mentioned in the literature, the mechanisms by which urinary light chains initiate the onset of renal failure are incompletely understood (18, 29 - 32). Two pathogenic mechanisms are most likely to be of major import: intratubular cast formation and direct tubular toxicity (18). It has been demonstrated that light chains can precipitate in tubules, leading to formation of obstructing, dense, intratubular casts, concurrently in the distal and the collecting tubules; this mechanism is supposed to initiate a giant cell reaction $(29,30,33)$.

Light chains with high affinity appear to produce obstructing intratubular casts; by contrast, light chains with moderate affinity for Tamm-Horsfall glycoprotein (THP) may still induce cast formation in the presence of hypovolemia (30). This process is prevented by a competitive inhibitor peptide that stops binding of light chains to THP, decreasing intratubular cast formation and preventing AKI in an animal model (34). Another contributing factor to THP binding and predisposing to cast nephropathy may be the isoelectric point (pI) of the light chain (18). Bence-Jones proteins with $\mathrm{pI}$ above 
5.1 (a level which is above the tubular fluid $\mathrm{pH}$ in the distal nephron) will have positive charges, a fact that may facilitate binding via charge interaction to anionic Tamm-Horsfall glycoprotein ( $\mathrm{pI}=3.2$ ) (29).

In fact, performing urinary alkalinization might be useful in reducing the binding capability of light chains to Tamm-Horsfall glycoprotein by rendering the light chains less cationic or even anionic, and by changing the charge on a single histidine residue in the binding site of THP(30).

In the onset of myeloma kidney, an important contributor to cast nephropathy is volume depletion, which may induce cast formation by slowing flow within the tubules, and may also lead to the formation of large aggregates $(18,29,30)$. Besides the above-mentioned mechanisms, other factors that are known as promoters for intratubular cast formation include:

- Loop diuretics, which increase luminal sodium chloride;

- Increased urinary calcium secondary to hypercalcemia, very common in MM;

- Radiocontrast media, which could interact with light chains deposition and can promote intratubular obstruction;

- NSAID's may precipitate the onset of AKI in $7-18 \%$ of patients $(16,35)$.

In a study performed by Weiss et al, intravenous infusion of monoclonal free light chains (FLCs) in rats increases pressure in the proximal tubule and concurrently decreases glomerular filtration rate (GFR); also, rats affected by monoclonal FLCs were identified of having intraluminal casts (36).

Another series of studies substantiate the fact that myeloma casts contain Tamm-Horsfall glycoprotein, and that the lesions occur initially in the distal tubules, were an optimum environment for co-precipitation with the monoclonal FLCs is assured $(16,29,30)$. Uromodullin or Tamm-Horsfall protein, the role of which is still incompletely established, is normally secreted by the epithelial cells of the thick ascending limb of the Henle's loop; this protein represents the matrix of mainly all urinary casts (29).
In a study performed by Ying et al, the authors showed that the secondary structure and aminoacid residues on the CDR3 of the FLCs were important determinants of the interaction with TammHorsfall glycoprotein. These findings allowed the development of an inhibiting cyclized competitor peptide, which inhibits cast precipitation (34).

It should be mentioned that in several animal studies, in which nephrotoxic human light chains were perfused into the rat nephron, the results showed that use of loop diuretics (such as Furosemide) can enhance cast formation by triggering the same mechanism, namely the increase in the luminal sodium chloride concentration (29). This finding is of major clinical importance, because loop diuretics are very often given without a proof of benefit, and perhaps deleteriously, to patients with myeloma cast nephropathy, in attempting to wash out obstructing casts.

\section{Tubular injury in multiple myeloma}

In some cases, light chain cast nephropathy is of minor importance, because in those cases the degree of renal injury correlates with tubular damage and atrophy (18). Tubular injury, as it was demonstrated for the proximal tubule, probably results from the reabsorption of some filtered light chains into the tubular cell. The accumulation of such chains in the proximal tubule epithelial cells may interfere with lysosomal function.

It is known that serum light chains are mainly reabsorbed by the proximal tubular epithelium, after binding to a heterodimeric receptor which consists of megalin and cubilin (37-39).

In a study performed by Li et al, by using target-specific short interfering (si)RNAs, the authors managed to silence the endocytic receptors megalin and cubilin genes in cultured human renal proximal tubule epithelial cells. Furthermore, in HK-2 cells exposed to kappa-light chains for almost 24 hours, light chain endocytosis was significantly reduced in either megalin- or cubilin-silenced cells, markedly but incompletely (39).

Moreover, it is well established that simultaneous silencing of both the cubilin and megalin genes, however, resulted in near-complete inhibi- 
tion of light chain endocytosis, as determined by measuring kappa-light chain concentration in cell cytoplasm and by flow cytometry (39-43). Also, light chain-induced cytokine responses (interleukin- 6 and monocyte chemoattractant protein-1) and epithelial-to-mesenchymal transition, as well as the associated cellular and morphological alterations were also markedly suppressed $(39,40,44)$.

Furthermore, Li et al managed to demonstrate that silencing megalin or cubilin individually has a lesser effect than silencing both of them. Megalin siRNA knockdown also had dramatic effects on cubilin levels, into the same degree as knocking down cubilin (38, 39, 41-44).

Acquired Fanconi syndrome. Some patients diagnosed with MM develop tubular dysfunction without renal failure. The proximal tubule is mainly affected, resulting in abnormalities, such as renal tubular acidosis, hypouricemia, hypophosphatemia, aminoaciduria due to renal phosphate wasting (45). In this scenario, the light chains that produce such lesions are resistant to degradation by proteases in tubular cell lysosomes. Accumulation of variable domain fragments, with subsequent intracellular crystal formation, is responsible for the tubular function impairment $(31,46)$ leading to a rare disorder known as Fanconi syndrome.

Free light chains undergo homotypic polymerization within the endolysosomal system of the proximal tubular epithelium to produce intracellular crystals, which are the pathological hallmark of this disease $(47,48)$.

This proximal tubular lesion represents a subset of gammopathy-associated crystal-storing histiocytosis, in which crystal-forming monoclonal proteins, mainly composed of heavy chains and typically k-FLC, accumulate into lysosomes of histiocytes in various soft tissues, such as kidneys, bone marrow, spleen, liver, and stomach (49). The reduced turnover of proximal tubule cells (PTCs) explains impaired tubular regeneration and repair in Fanconi syndrome associated to MM.

The decreased proliferation of myeloma cells which produce the same monoclonal $\kappa L C$ could explain the frequent association of Fanconi syndrome with silent forms of multiple myeloma (50).

Proximal tubulopathy in multiple myeloma. Free light chains (FLCs) determine cytotoxic effects through mechanisms that are different from crystal formation. It was demonstrated that infusion in the proximal convoluted tubules of human monoclonal FLCs promotes functional and morphologic evidence of toxicity, associated with an expanding endolysosomal system and occasional intracellular crystal formation (51).

It is demonstrated that FLCs may have direct toxic effects on proximal tubular cells through blockade of glucose, aminoacids, and phosphate transport $(40,51,52)$.

Recently, it has been established that monoclonal FLCs, but not polyclonal light chains, may generate intracellular oxidative stress, particularly hydrogen peroxide (53). These molecules promote redox-signaling events that result in production of chemokines and cytokines, but also in apoptosis of the proximal tubular cells (53-56).

Experimental studies were performed in order to understand the pathological mechanisms of tubulointerstitial renal fibrosis in the course of multiple myeloma. Li et al evaluated the role of epithelial-mesenchymal transition (EMT) in the process of renal fibrosis in multiple myeloma (44).

The results of their study show that light chains directly induce EMT in humans, but also marked cellular morphological alterations in proximal tubule epithelial cells (PTECs), which are accompanied by increased expression of profibrotic transforming growth factor $\beta 1$ (TGF- $\beta 1$ ), fibroblast-specific protein-1 (FSP-1), and extracellular matrix components. In conclusion, the authors demonstrated that FLCs are acting like a direct stimulus for EMT in PTECs, a process that involves multiple cytokines, but seems to be independent of the action of TGF- $\beta 1$ (44).

Focusing on the particular role played in the management of multiple myeloma cases by using novel therapy agents, such as Bortezomib, Sarkozi et al studied its direct effects on PTECs as compared with glomerular mesangial 
cells (GMCs). After 24 hours of stimulation, a molecule of $50 \mathrm{nM}$ Bortezomib led to a 6.37fold induction of apoptosis and markedly activated caspase- 9 and -3 in mesangial cells, but not in the proximal tubules (57).

Furthermore, it was established that only in the proximal tubule epithelium, Bortezomib led to a time-dependent predominance of antiapoptotic genes as compared to the proapoptotic ones. Moreover, the potential role of Bortezomib as a blocker of both NF-kB activation and cell survival was thoroughly examined in various renal cell types (57).

Interleukin-6. This molecule is an important growth factor for plasma cells, as is the case with multiple myeloma. The process of interleukin-6 (IL-6) stimulation over plasma cells could be enhanced in skeletal bones where myeloma cells may upregulate IL-6 production by osteoblasts (58). Several animal studies suggest that IL-6 is involved in the pathogenesis of myeloma cast nephropathy. In fact, transgenic mice with an extra IL-6 gene will suffer from polyclonal gammopathy and AKI with formation of cast nephropathy (59). The pathogenic mechanisms involved in this process are incompletely understood, since renal failure is not seen in individuals with polyclonal gammopathy. One possible factor involves the stimulation of hepatic release of acute phase reactants by IL- 6 ; these proteins may promote cast formation or act indirectly by impairing light chain reabsorption (59).

In a study performed by Sengul et al, it was underlined that endocytosis of light chains induces cytokine release through activation of NF-kB in human proximal tubule cells. Renal involvement in multiple myeloma often leads to proteinuric states, which increase cytokine production through endocytosis of filtered proteins by PTCs. This is the most important mechanism forwarded in the explanation of tubulointerstitial injury and progressive kidney disease in the course of MM (60).

Studying different light chains involved in the production of cytokines in cultured human proximal tubule cells, Sengul et al managed to evidence the release of various inter- leukins, such as IL-6, interleukin-8 (IL-8) and monocyte chemoattractant protein-1 (MCP-1); in contrast, the results showed that serum albumin had no effect on cytokine production, even at very high concentrations (60).

These assessments demonstrated the involvement of light chain endocytosis in the production of inflammatory cytokines, mainly through activation of NF-kB (61).

\section{Diagnosis}

The onset of myeloma cast nephropathy should be suspected in patients over the age of 40 years who present with unexplained abrupt decline of renal function. A significant percentage of such patients was not previously diagnosed with $\mathrm{MM}$ or other monoclonal gammopathy $(35,62)$.

When performing urinalysis, urine dipsticks remain negative or only trace-positive for proteins; meanwhile, the sediment is typically bland. Light chains are usually undetected by the urinary dipstick, which is more sensitive for albumin. By contrast, patients with amyloidosis or light chain deposition disease typically present with nephrotic syndrome (heavy proteinuria), hypoalbuminemia, and edema; in such cases the urine dipstick is highly positive for proteins.

In the rare cases when myeloma cast nephropathy is present concurrently with light chain deposition disease or amyloidosis, the clinical features are usually determined by the glomerular disease process (35). The urine in patients with AKI or CKD, with bland urine sediment, negative or trace-positive dipstick requires mandatory testing with sulfosalicylic acid (SSA), which is able to detect all proteins. In fact, markedly positive SSA test, with relatively negative dipstick, is highly indicative of non-albumin proteins, such as light chains (Bence-Jones protein).

Serum protein electrophoresis, immunofixation, and free light chain assay should be obtained for every patient suspected of having multiple myeloma. In fact, a 24-hour urine collec- 
tion sample and a serum sample should be analyzed by electrophoresis and immunofixation in order to confirm the origin of the monoclonal protein, and also to assess the amount of monoclonal light chain. Quantitative interpretation of these results is unreliable when the GFR is reduced, since the urinary excretion of monoclonal free light chains decreases with declining GFR (63).

\section{Conflicts of interest: none to declare.}

\section{Abbreviations}

AKI - acute kidney injury;

CKD - chronic kidney disease;

EMT - epithelial-mesenchymal transition;

ESR - erythrocyte sedimentation rate;

FLC - free light chains;

FSGS - focal segmental glomerulosclerosis;

GFR - glomerular filtration rate;

GMC - glomerular mesangial cells;

$\mathrm{Hb}$ - haemoglobin;

IL-6 - interleukin-6;

IL-8 - interleukin-8;

LCDD - light chain deposition disease;

MCP-1 - monocyte chemoattractant protein-1;

MM - multiple myeloma;

NSAID - non-steroidal anti-inflammatory drug;

PTC - proximal tubule cells;

PTEC - proximal tubule epithelial cells;

RNA - ribonucleic acid;

SPEP - serum protein electrophoresis;

SSA - sulfosalicylic acid;

TGF- $\beta 1$ - transforming growth factor $\beta 1$;

THP - Tamm-Horsfall glycoprotein;

UPEP - urinary protein electrophoresis.

\section{References}

1. Kariyawasan CC, Hughes DA, Jayatillake MM, Mehta AB. Multiple myeloma: causes and consequences of delay in diagnosis. QJM 2007; 100:635.

2. Siegel R, Naishadham D, Jemal A. Cancer statistics, 2012. CA Cancer J Clin 2012; 62:10.

3. Phekoo KJ, Schey SA, Richards MA, Bevan DH, Bell $\mathrm{S}$, Gillett D, et al. A population study to define the incidence and survival of multiple myeloma in a National Health Service Region in UK. Br J Haematol 2004; 127:299.

4. Sant M, Allemani C, Tereanu C, De Angelis R, Capoc- accia R, Visser O, et al. Incidence of hematologic malignancies in Europe by morphologic subtype: results of the HAEMACARE project. Blood 2010; 116:3724.

5. Smith A, Howell D, Patmore R, Jack A, Roman E. Incidence of haematological malignancy by sub-type: a report from the Haematological Malignancy Research Network. Br J Cancer 2011; 105:1684.

6. Kyle RA, Gertz MA, Witzig TE, Lust JA, Lacy MQ, Dispenzieri A, et al. Review of 1027 patients with newly diagnosed multiple myeloma. Mayo Clin Proc 2003; 78:21.

7. Waxman AJ, Mink PJ, Devesa SS, Anderson WF, Weiss BM, Kristinsson SY, et al. Racial disparities in incidence and outcome in multiple myeloma: a population-based study. Blood 2010; 116:5501.

8. Huang SY, Yao M, Tang JL, Lee WC, Tsay W, Cheng AL, et al. Epidemiology of multiple myeloma in Taiwan: increasing incidence for the past 25 years and higher prevalence of extramedullary myeloma in patients younger than 55 years. Cancer 2007; 110:896.

9. Lynch HT, Sanger WG, Pirruccello S, Quinn-Laquer B, Weisenburger DD. Familial multiple myeloma: a family study and review of the literature. J Natl Cancer Inst 2001; 93(19):1479

10. Winearls CG. Acute myeloma kidney. Kidney Int 1995; $48: 1347$.

11. Smith A, Wisloff F, Samson D; UK Myeloma Forum; Nordic Myeloma Study Group; British Committee for Standards in Haematology. Guidelines on the diagnosis and management of multiple myeloma 2005. Br J Haematol 2006; 132:410.

12. International Myeloma Working Group. Criteria for the classification of monoclonal gammopathies, multiple myeloma and related disorders: a report of the International Myeloma Working Group. Br J Haematol 2003; 121:749.

13. Rajkumar SV, Dispenzieri A, Fonseca R, Lacy MQ, Geyer S, Lust JA, et al. Thalidomide for previously untreated indolent or smoldering multiple myeloma. Leukemia 2001; 15:1274.

14. Rajkumar SV, Dispenzieri A, Kyle RA. Monoclonal gammopathy of undetermined significance, Waldenström macroglobulinemia, AL amyloidosis, and related plasma cell disorders: diagnosis and treatment. Mayo Clin Proc 2006; 81:693.

15. Bladé J, Fernández-Llama P, Bosch F, Montolíu J, Lens XM, Montoto S, et al. Renal failure in multiple myeloma: presenting features and predictors of outcome in 94 patients from a single institution. Arch Intern Med 1998; 158:1889.

16. Sakhuja V, Jha V, Varma S, Joshi K, Gupta KL, Sud $\mathrm{K}$, et al. Renal involvement in multiple myeloma: a 10year study. Ren Fail 2000; 22:465

17. http://www.uptodate.com/contents/types-of-renal-disease-in-multiple-myeloma

18. Sanders PW. Mechanisms of Light Chain Injury 
along the Tubular Nephron. J Am Soc Nephrol 2012; 23(11): 1777

19. Dennen P, Parikh CR. Biomarkers of acute kidney injury: can we replace serum creatinine? Clin Nephrol 2007; 68(5):269.

20. Siew ED, Ware LB, Ikizler TA. Biological markers of acute kidney injury. J Am Soc Nephrol 2011; 22:810.

21. Mussap M, Dalla Vestra M, Fioretto P, Saller A, Varagnolo $\mathrm{M}$, et al. Cystatin $\mathrm{C}$ is a more sensitive marker than creatinine for the estimation of GFR in type 2 diabetic patients. Kidney Int 2002; 61:1453.

22. Herget-Rosenthal S, Marggraf G, Hüsing J, Göring F, Pietruck F, Janssen O, et al. Early detection of acute renal failure by serum cystatin C. Kidney Int 2004; 66:1115

23. Edelstein CL, Faubel S. Biomarkers in acute kidney injury, in Edelstein CL. Biomarkers in Kidney Disease. Academic Press Elsevier 2011; pp.177-232.

24. Fassett RG, Venuthurupalli SK, Gobe GC, Coombes JS, Cooper MA, Hoy WE. Biomarkers in chronic kidney disease: a review. Kidney Int 2011; 80:806.

25. Vaidya VS, Ramirez V, Ichimura T, Bobadilla NA, Bonventre JV. Urinary kidney injury molecule-1: a sensitive quantitative biomarker for early detection of kidney tubular injury. Am J Physiol Renal Physiol 2006; 290:F517.

26. Han WK, Waikar SS, Johnson A, Betensky RA, Dent CL, Devarajan P, et al. Urinary biomarkers in the early diagnosis of acute kidney injury. Kidney Int 2008; 73:863.

27. Montseny JJ, Kleinknecht D, Meyrier A, Vanhille P, Simon P, Pruna A, et al. Long-term outcome according to renal histological lesions in 118 patients with monoclonal gammopathies. Nephrol Dial Transplant 1998; 13:1438.

28. Nasr SH, Valeri AM, Sethi S, Fidler ME, Cornell LD, Gertz MA, et al. Clinicopathologic correlations in multiple myeloma: a case series of 190 patients with kidney biopsies. Am J Kidney Dis 2012; 59:786.

29. Sanders PW, Booker BB. Pathobiology of cast nephropathy from human Bence Jones proteins. J Clin Invest 1992; 89:630.

30. Huang ZQ, Sanders PW. Localization of a single binding site for immunoglobulin light chains on human Tamm-Horsfall glycoprotein. J Clin Invest 1997; 99:732.

31. Decourt C, Rocca A, Bridoux F, Vrtovsnik F, Preud'homme JL, Cogné M, et al. Mutational analysis in murine models for myeloma-associated Fanconi's syndrome or cast myeloma nephropathy. Blood 1999; 94:3559.

32. Solomon A, Weiss DT, Kattine AA. Nephrotoxic potential of Bence Jones proteins. N Engl J Med 1991; 324:1845.

33. Pirani CL, Silva F, D'Agati V, Chander P, Striker LM. Renal lesions in plasma cell dyscrasias: ultrastructural observations. Am J Kidney Dis 1987; 10:208

34. Ying WZ, Allen CE, Curtis LM, Aaron KJ, Sanders PW. Mechanism and prevention of acute kidney injury from cast nephropathy in a rodent model. J Clin Invest
2012; 122:1777.

35. Magee C, Vella JP, Tormey WP, Walshe JJ. Multiple myeloma and renal failure: one center's experience. Ren Fail 1998; 20:597.

36. Weiss JH, Williams RH, Galla JH, Gottschall JL, Rees ED, Bhathena D, et al. Pathophysiology of acute Bence-Jones protein nephrotoxicity in the rat. Kidney Int 1981; 20:198

37. Batuman V, Verroust PJ, Navar GL, Kaysen JH, Goda FO, Campbell WC, et al. Myeloma light chains are ligands for cubilin (gp 280). Am J Physiol 1998; 275:F246.

38. Klassen RB, Allen PL, Batuman V, Crenshaw K, Hammond TG. Light chains are a ligand for megalin. J Appl Physiol 2005; 98:257.

39. Li M, Balamuthusamy S, Simon EE, Batuman V. Silencing megalin and cubilin genes inhibits myeloma light chain endocytosis and ameliorates toxicity in human renal proximal tubule epithelial cells. Am J Physiol Renal 2008; 295:F82.

40. Guan S, el-Dahr S, Dipp S, Batuman V. Inhibition of Na-K-ATPase activity and gene expression by a myeloma light chain in proximal tubule cells. J Investig Med 1999; 47:496.

41. Diwakar R, Pearson AL, Colville-Nash P, Brunskill NJ, Dockrell ME. The role played by endocytosis in albumin-induced secretion of TGF-1 by proximal tubular epithelial cells. Am J Physiol Renal Physiol 2007; 292:F1464.

42. Dreisbach AW, Batuman V. Low-molecular-weight protein competition for binding sites on renal brush border membranes. Ren Physiol Biochem 1994; 17:287.

43. Verroust PJ, Christensen EI. Megalin and cubilin the story of two multipurpose receptors unfolds. Nephrol Dial Transplant 2002; 17:1867.

44. Li M, Hering-Smith KS, Simon EE, Batuman V. Myeloma light chains induce epithelial-mesenchymal transition in human renal proximal tubule epithelial cells. Nephrol Dial Transplant 2008; 23(3):860.

45. Ma CX, Lacy MQ, Rompala JF, Dispenzieri A, Rajkumar SV, Greipp PR, et al. Acquired Fanconi syndrome is an indolent disorder in the absence of overt multiple myeloma. Blood 2004; 104:40.

46. Lajoie G, Leung R, Bargman JM. Clinical, biochemi$\mathrm{cal}$, and pathological features in a patient with plasma cell dyscrasia and Fanconi syndrome. Ultrastruct Pathol 2000; 24:221.

47. Mead GP, Carr-Smith HD, Drayson MT, Morgan GJ, Child JA, Bradwell AR. Serum free light chains for monitoring multiple myeloma. Br J Haematol 2004; 126:348.

48. Maldonado JE, Velosa JA, Kyle RA, Wagoner RD, Holley KE, Salassa RM. Fanconi syndrome in adults. A manifestation of a latent form of myeloma. Am J Med 1975; 58:354.

49. Merlini G, Stone MJ. Dangerous small B-cell clones. Blood 2006; 108:2520 
50. El Hamel C, Aldigier JC, Oblet C, Laffleur B, Bridoux F, Cogné M. Specific impairment of proximal tubular cell proliferation by a monoclonal кlight chain responsible for Fanconi syndrome. Nephrol Dial Transplant 2012; $27: 4368$.

51. Sanders PW, Herrera GA, Galla JH. Human BenceJones protein toxicity in rat proximal tubule epithelium in vivo. Kidney Int 1987; 32:851.

52. Batuman V. Proximal tubular injury in myeloma. Contrib Nephrol 2007; 153:87.

53. Wang PX, Sanders PW. Immunoglobulin light chains gene rate hydrogen peroxide. J Am Soc Nephrol 2007; 18:1239.

54. Basnayake K, Ying WZ, Wang PX, Sanders PW. Immunoglobulin light chains activate tubular epithelial cells through redox signaling. J Am Soc Nephrol 2010; 21:1165.

55. Ying WZ, Wang PX, Aaron KJ, Basnayake K, Sanders PW. Immunoglobulin light chains activate nuclear factor-kB in renal epithelial cells through a Src-dependent mechanism. Blood 2011; 117:1301.

56. Ying WZ, Wang PX, Sanders PW. Pivotal role of apoptosis signal-regulating kinase 1 in monoclonal free light chain-mediated apoptosis. Am J Pathol 2012; 180:41. 57. Sarközi R, Perco P, Hochegger K, Enrich J, Wiesinger M, Pirklbauer M, et al. Bortezomib-induced survival signals and genes in human proximal tubular cells. J Pharmacol Exp Ther 2008; 327(3):645.

58. Barillé S, Collette M, Bataille R, Amiot M. Myeloma cells upregulate interleukin-6 secretion in osteoblastic cells through cell-to-cell contact but downregulate osteocalcin. Blood 1995; 86:3151.

59. Fattori E, Della Rocca C, Costa P, Giorgio M, Dente B, Pozzi L, et al. Development of progressive kidney damage and myeloma kidney in interleukin-6 transgenic mice. Blood 1994; 83:2570.

60. Sengul S, Zwizinski C, Simon EE, Kapasi A, Singhal PC, Batuman V. Endocytosis of light chains induces cytokines through activation of NF-kappaB in human proximal tubule cells. Kidney Int 2002; 62:1977.

61. Sengul S, Zwizinski C, Batuman V. Role of MAPK pathways in light chain-induced cytokine production in human proximal tubule cells. Am J Physiol Renal Physiol 2003; 284:F1245

62. Lin J, Markowitz GS, Valeri AM, Kambham N, Sherman WH, Appel GB, et al. Renal monoclonal immunoglobulin deposition disease: the disease spectrum. J Am Soc Nephrol 2001; 12:1482

63. Nowrousian MR, Brandhorst D, Sammet C, Kellert M, Daniels R, Schuett P, et al. Serum free light chain analysis and urine immunofixation electrophoresis in patients with multiple myeloma. Clin Cancer Res 2005; 11:8706 